\title{
Increased chronic kidney disease development and progression in diabetic patients after appendectomy: a population-based cohort study
}

\author{
Chin-Hua Chang ${ }^{1}$, Chew-Teng Kor ${ }^{2,3}{ }^{\text {, }}$, Chia-Lin Wu ${ }^{1,4,5}$, Ping-Fang Chiu ${ }^{1,6}$, Jhao-Rong Li ${ }^{1}$, Chun-Chieh Tsai \\ ${ }^{1}$, Teng-Hsiang Chang ${ }^{1}$, Chia-chu Chang ${ }^{\text {Corresp. } 1,4,6,7,8}$ \\ 1 Department of Internal Medicine, Changhua Christian hospital, Changhua, Taiwan \\ 2 Department of Internal Medicine Research Center, Changhua Christian hospital, Changhua, Taiwan \\ 3 Graduate Institute of Statistics and Information Science, National Changhua University of Education, Changhua, Taiwan \\ 4 Department of Environmental and Precision Medicine Laboratory, Changhua Christian Hospital, Changhua, Lithuania \\ 5 Institute of Clinical Medicine, National Yang-Ming University, Taipei, Taiwan \\ 6 School of Medicine, Chung-Shan Medical University, Taichung, Taiwan \\ 7 Department of Internal Medicine, Kuang Tien General Hospital, Taichung, Taiwan \\ 8 Department of Nutrition, Hungkuang University, Taichung, Taiwan \\ Corresponding Author: Chia-chu Chang \\ Email address: chiachu@cch.org.tw
}

Background: The vermiform appendix serves as a "safe house" for maintaining normal gut bacteria and appendectomy may impair the intestinal microbiota. Appendectomy is expected to profoundly alter the immune system and modulate the pathogenic inflammatory immune responses of the gut. Recent studies have shown that a dysbiotic gut increases the risk of cardiovascular disease and chronic kidney disease (CKD). Therefore, we hypothesized that appendectomy would increase the risk of CKD. Methods: This nationwide, population-based, propensity-score-matched cohort study included 10,383 patients who underwent appendectomy and 41,532 propensity-score-matched controls. Data were collected by the National Health Insurance Research Database of Taiwan from 2000 to 2013. We examined the associations between appendectomy and CKD and end-stage renal disease (ESRD). The major outcome was a new diagnosis of CKD based on an outpatient diagnosis made at least three times or hospital discharge diagnosis made once during the follow-up period. ESRD was defined as undergoing dialysis therapy for at least 90 days, as in previous studies. Results: The incidence rates of CKD and ESRD were higher in the appendectomy group than in the control cohort (CKD: 6.52 vs. 5.93 per 1000 person-years, respectively; ESRD: 0.49 vs. 0.31 per 1000 person-years, respectively). Appendectomy patients also had a higher risk of developing CKD (adjusted hazard ratio [aHR] 1.13; 95\% Cl 1.01-1.26; $\mathrm{P}=0.037$ ) and ESRD (aHR 1.59; 95\% $\mathrm{Cl} 1.06-2.37 ; \mathrm{P}=$ 0.024 ) than control group patients. Subgroup analysis showed that appendectomy patients with concomitant diabetes mellitus (aHR 2.08; $\mathrm{P}=0.004)$ were at higher risk of incident 
ESRD than those without diabetes mellitus. The interaction effects of appendectomy and diabetes mellitus were significant for ESRD risk $(P=0.022)$; no interaction effect was found for $C K D$ risk $(P=0.555)$. Conclusions: Appendectomy increases the risk of developing CKD and ESRD, especially in diabetic patients. Physicians should pay close attention to renal function prognosis in appendectomy patients. 
1 Increased chronic kidney disease development and progression in diabetic patients

2 after appendectomy: a population-based cohort study

3

4 Chin-Hua Chang, ${ }^{* 1}$ Chew-Teng Kor, ${ }^{* 2,3}$ Chia-Lin Wu, ${ }^{1,4,5}$ Ping-Fang Chiu, ${ }^{1,6}$ Jhao-Rong Li, ${ }^{1}$

5 Chun-Chieh Tsai, ${ }^{1}$ Teng-Hsiang Chang, ${ }^{1}$ Chia-Chu Chang, $, 1,4,6,7,8$

6

7 'Division of Nephrology, Department of Internal Medicine, Changhua Christian Hospital,

8 Changhua, Taiwan

9 Internal Medicine Research Center, Changhua Christian Hospital, Changhua, Taiwan

$10{ }^{3}$ Graduate Institute of Statistics and Information Science, National Changhua University of

11 Education, Changhua, Taiwan

$12{ }^{4}$ Environmental and Precision Medicine Laboratory, Changhua Christian Hospital, Changhua,

13 Taiwan

$14{ }^{5}$ Institute of Clinical Medicine, National Yang-Ming University, Taipei, Taiwan

$15{ }^{6}$ School of Medicine, Chung-Shan Medical University, Taichung, Taiwan

$16{ }^{7}$ Department of Internal Medicine, Kuang Tien General Hospital, Taichung, Taiwan

$17{ }^{8}$ Department of Nutrition, Hungkuang University, Taichung, Taiwan

$18 *$ Contributed equally as first authors

19

20 Corresponding author:

21 Chia-Chu Chang, MD, PhD ; E-mail: 27509@cch.org.tw 
34

35

36

37

38

39

40

41

42

43

44

45

\section{Abstract}

Background. Because the vermiform appendix serves as a "safe house" for maintaining normal gut bacteria, appendectomy may impair the intestinal microbiota. Appendectomy is expected to profoundly alter the immune system and modulate the pathogenic inflammatory immune responses of the gut. Recent studies have shown that a dysbiotic gut increases the risk of cardiovascular disease and chronic kidney disease (CKD). Therefore, we hypothesized that appendectomy would increase the risk of CKD.

Methods. This nationwide, population-based, propensity-score-matched cohort study included 10,383 patients who underwent appendectomy and 41,532 propensity-score-matched controls. Data were collected by the National Health Insurance Research Database of Taiwan from 2000 to 2013. We examined the associations between appendectomy and CKD and end-stage renal disease (ESRD). The major outcome was a new diagnosis of CKD based on an outpatient diagnosis made at least three times or hospital discharge diagnosis made once during the follow-up period. ESRD was defined as undergoing dialysis therapy for at least 90 days, as in previous studies.

Results. The incidence rates of CKD and ESRD were higher in the appendectomy group than in the control cohort (CKD: 6.52 vs. 5.93, respectively, per 1000 person-years; ESRD: 0.49 vs. 0.31, respectively, per 1000 person-years). Appendectomy patients also had a higher risk of developing CKD (adjusted hazard ratio [aHR] 1.13, 95\% CI 1.01-1.26, $\mathrm{P}=0.037)$ and ESRD (aHR 1.59, 95\% CI 1.06-2.37, $\mathrm{P}=0.024)$ than control-group patients. Subgroup analysis showed that appendectomy patients with concomitant diabetes mellitus were at higher risk of incident ESRD than those without diabetes mellitus (aHR 2.08, $\mathrm{P}=0.004$ ). The interaction effects of appendectomy and diabetes mellitus were significant for ESRD risk $(\mathrm{P}=0.022)$; no interaction effect was found for CKD risk $(\mathrm{P}=0.555)$.

Conclusions: Appendectomy increases the risk of developing CKD and ESRD, especially in diabetic patients. Physicians should pay close attention to renal function prognosis in appendectomy patients.

3

4

65

66


70

\section{Introduction}

72 Chronic kidney disease (CKD) is a global public health problem affecting up to $10 \%$ of the population worldwide ${ }^{1}$. CKD influences kidney structure and function and typically results in endstage renal disease (ESRD). Better approaches for the prevention, early detection, and treatment of CKD are needed. ${ }^{2}$ Therefore, it is important to recognize the risk factors for CKD. The vermiform appendix serves as a "safe house" for maintaining normal gut bacteria and can provide support for bacterial growth. ${ }^{3,4}$ Guinane et al. found that the appendix possesses a microbial diversity sufficient to reconstitute the microbiome of the colon. ${ }^{5}$ The appendix also contains the highest concentration of gut-associated lymphoid tissue, which has numerous functions. ${ }^{6}$ Appendectomy is expected to profoundly alter the immune system and modulate the pathogenic inflammatory immune responses of the gut. ${ }^{6}$ Furthermore, studies have shown that appendectomy-related impairment of the microbiota may lead to dysbiosis and induce various diseases, including ulcerative colitis, Crohn's disease, Clostridium difficile infection, colorectal cancer, rheumatoid arthritis, and cardiovascular disease. ${ }^{6-9}$

To date, there is no evidence confirming that appendectomy contributes to CKD. In this study, we evaluated the correlation between prior appendectomy and the occurrence of CKD and ESRD.

\section{Materials and methods}

\section{Data source}

Data for this study were retrieved from the Taiwan National Health Insurance Research Database (NHIRD), which contains data from all medical claims in the Taiwan National Health Insurance Program. This insurance program started in 1995 and covers $>99 \%$ of the Taiwanese population of approximately 23 million people. Our research dataset was the Longitudinal Health Insurance Database 2005 (LHID2005), which includes the data from one million patients randomly selected from the NHIRD in 2005 and longitudinally linked with the NHIRD from 1996 to 2013. LHID2005 is managed and established by the National Health Insurance. Diagnostic codes used in the LHID2005 to identify diseases are taken from the International Classification of Diseases, Ninth Revision, Clinical Modification (ICD-9-CM). These diagnostic codes have been shown to have high accuracy and validity. ${ }^{10-12}$ This study was approved after a full ethical review by the Institutional Review Board of the Changhua Christian Hospital (approval number 151219), which waived the need for consent. Data were accessed anonymously.

\section{Study population}

We used a 4-year look-back period (1996-1999) for newly identified appendectomy patients. From the hospitalization database of the LHID2005, we identified patients aged 18 to 100 years who 
106 underwent appendectomy from 2000 to 2013 (ICD-9-CM codes 47.0 and 47.1). The index date 107 was defined as the date of appendectomy. Each identified appendectomy patient was randomly 108 matched with four control patients according to propensity score. We excluded patients with a 109 history of CKD before the index date, those aged $<18$ or $>100$ years, those with incomplete 110 demographic data, and those with fewer than 30 days of follow-up.

111

112 Outcomes and relevant variables

113 Outcomes and comorbidities were diagnosed according to ICD-9 codes. The major outcome was 114 a new diagnosis of CKD (ICD-9 codes 580-585), based on an outpatient diagnosis made at least 115 three times or hospital discharge diagnosis made once during the follow-up period. ESRD was 116 defined as undergoing dialysis therapy for at least 90 days, as in previous studies. ${ }^{13-15}$

117 The following comorbidities potentially related to CKD were investigated: hypertension (ICD-9 118 401-405), diabetes mellitus (DM; ICD-9 250), hyperlipidemia (ICD-9 272), coronary artery 119 disease (CAD; ICD-9 410-414), congestive heart failure (CHF; ICD-9 402-404, 425.4-425.9, 120 428), arrhythmia (ICD-9 427), stroke (ICD-9 430-438), peripheral artery occlusive disease 121 (PAOD; ICD-9 443-444), gout (ICD-9 274), and chronic obstructive pulmonary disease (COPD; 122 ICD-9 416.8, 416.9, 490-505, 506.4, 508, 508.1). Charlson Comorbidity Index (CCI) scores were 123 used to measure the severity of comorbidities at baseline. ${ }^{16}$ Some long-term medications have been 124 associated with renal outcomes, including antidiabetic agents, angiotensin-converting-enzyme 125 inhibitors, angiotensin II receptor blockers, beta blockers, diuretics, nonsteroidal anti126 inflammatory drugs (NSAIDs), analgesic drugs other than NSAIDs, and statins. All study subjects 127 were followed from the index date until the first diagnosis of CKD or ESRD, withdrawal from the 128 insurance system, or at the end of 2013.

129

130

Statistical analysis

131 Demographic and clinical characteristics in the appendectomy and non-appendectomy cohorts are 132 presented as number (percentage) and mean \pm standard deviation (SD). Differences in categorical

133

134 135 136 and continuous variables were compared between the cohorts with chi-square tests and Student's t-tests, respectively. To reduce the potential bias from uncontrolled confounding, we performed propensity-score-matching studies. To achieve a maximum power to illustrate a significant association between appendectomy and CKD, we used a 1:4 propensity-score-matching approach in our study. Propensity scores were calculated with multivariate logistic regression to predict the likelihood of undergoing appendectomy (Supplemental Table 1). The incidence of CKD was calculated as the number of CKD events occurring during the follow-up year, divided by the total follow-up person-years for all subjects.

The Cox proportional hazards regression model with competing risks of death was applied to 
142 estimate the hazard ratio (HR) and 95\% confidence interval (CI) for risk of incident CKD in

143 patients after appendectomy compared with the non-appendectomy cohort. Multivariate Cox's

144 hazards analysis was used with the Fine-Grey competing risks model to estimate adjusted hazard

145 ratios (aHRs), adjusting for the following confounders: appendectomy, demographic factors (age,

146 sex, clinical visit frequency, and income), comorbidities (hypertension, DM, hyperlipidemia, gout,

147 stroke, CAD, CHF, arrhythmia, PAOD, COPD, and CCI score), and long-term use of medications

148 (statins, antidiabetic drugs, antihypertensive drugs, NSAIDs, and analgesic drugs other than

149 NSAIDs). Subgroup analyses were used to distinguish CKD and ESRD risks in patients after 150 appendectomy and in the control cohort according to various subpopulations. The cumulative

151 incidence of CKD and ESRD in both study cohorts were examined with the Fine-Grey sub-

152 distribution hazard approach and compared with Grey's tests. All statistical analyses were

153 performed with SAS 9.4 software (SAS Institute Inc., Cary, NC). A two-tailed P value $<0.05$ was

154 considered statistically significant.

155

156

Results

157 Characteristics of the study population

158 Figure 1 shows a flowchart of the subject selection process and Table 1 shows the characteristics 159 of the study population. This study comprised 51,915 patients, including 10,383 with new 160 appendectomy and 41,532 propensity-score-matched controls not diagnosed with appendectomy. 161 The follow-up times (mean $\pm \mathrm{SD}$ ) in these cohorts were $5.81 \pm 3.98$ years and $6.66 \pm 4.02$ years, 162 respectively. There was no significant difference in sex or age between the appendectomy and 163 non-appendectomy cohorts. The prevalence of comorbidities, including hypertension, DM, 164 hyperlipidemia, CAD, CHF, arrhythmia, stroke, PAOD, gout, and COPD, were similar in both 165 cohorts (Table 1). Compared with the control cohort, patients with appendectomy were slightly 166 less likely to be taking long-term angiotensin-converting-enzyme inhibitors or angiotensin II 167 receptor blockers $(5.94 \%$ vs. $6.48 \%, \mathrm{P}=0.0433)$.

168

169

Long-term risk of incident CKD and ESRD

170

During the follow-up period, the proportion of patients who developed CKD or ESRD was significantly higher among appendectomy patients than in the control cohort (CKD: 4.34\% vs.

$1723.44 \%, \mathrm{P}<0.0001$; ESRD: 0.34\% vs. 0.18\%, $\mathrm{P}=0.0019$; Table 1). The cumulative incidence 173 curve of CKD and ESRD according to the Fine-Grey method was also significantly higher for 174 subjects with appendectomy than for the control cohort (Grey's test: $\mathrm{P}=0.012$ for CKD, $\mathrm{P}=0.014$ 175 for ESRD; Fig. 2A and 2B). The incidence rates of CKD and ESRD were 6.52 and 0.49, 176 respectively, per 1000 person-years for appendectomy patients and 5.93 and 0.31, respectively, 177 per 1000 person-years for the control cohort (Table 2). To evaluate the reliability of our results, 
178 we used three models to adjust the risk for incident CKD and ESRD among appendectomy patients 179 compared with the control cohort (Table 2). According to propensity-score-matched data, the risks 180 of CKD and ESRD were significantly higher among appendectomy patients than among controls 181 (CKD: crude HR [cHR] 1.15, 95\% CI 1.03-1.27, P = 0.012; ESRD: cHR 1.65, 95\% CI 1.10-2.47, $182 \mathrm{P}=0.014)$. Even after adjustment for the propensity score, the risk of CKD and ESRD remained 183 higher in the appendectomy group than in the control cohort (CKD: adjusted HR (aHR) 1.13, 95\% 184 CI 1.01-1.25, P = 0.029; ESRD: aHR 1.62, 95\% CI 1.09-2.42, $\mathrm{P}=0.018$ ). Finally, we performed 185 multivariate analysis adjusting for all confounding variables listed in Table 1 . The results of this 186 analysis showed that the risks of CKD and ESRD were similarly higher in the appendectomy group

187

188

189

190 191

192 193 194 195 196 197 198

199 200

201

202 203 204

205

206

207

208

209

210

211

212

213 than in the control cohort (CKD: aHR 1.13, 95\% CI 1.01-1.26, P = 0.037; ESRD: aHR 1.59, 95\% CI $1.06-2.37, \mathrm{P}=0.024)$.

Subgroup analysis of CKD risk according to age, sex, comorbid conditions, and DM in appendectomy patients versus control cohort

Table 3 shows that the HR for incident CKD was significantly higher in the appendectomy group than in the control cohort only for males (aHR 1.16, 95\% CI 1.00-1.34, P = 0.045) and for those without comorbid conditions (aHR 1.29, 95\% CI 1.08-1.55, P =0.006). The association between appendectomy and CKD risk was absent in female patients, in individual age groups, and in those with comorbid conditions ( $1-2$ versus $\geq 3$ comorbid diseases), including DM. The interactions between all stratified subgroups and appendectomy were not significant (all $\mathrm{P}$ interaction $>0.05$ ).

Subgroup analysis of ESRD risk according to age, sex, comorbid conditions, and DM in appendectomy patients versus control cohort

Table 4 shows that the HR for incident ESRD was significantly higher for appendectomy patients than for the control cohort only among patients who were middle-aged (30-64 years) (aHR 2.05, 95\% CI 1.17-3.57, $\mathrm{P}=0.012$ ) and that there was a marginally higher risk among females (aHR $1.68,95 \%$ CI $0.97-2.92, \mathrm{P}=0.067)$. The association between appendectomy and ESRD risk was absent for male patients, for other age groups ( $<30$ years and $\geq 65$ years), and for those with comorbid conditions $(0,1-2$, and $\geq 3$ comorbid diseases). However, the interactions between sex, age group, comorbid conditions, and appendectomy were not significant (all $\mathrm{P}_{\text {interaction }}>0.05$ ). In particular, appendectomy patients with concomitant DM were found to have a significantly increased risk of ESRD compared with the control cohort patients with DM (aHR 2.08, 95\% CI 1.27-3.43, $\mathrm{P}=0.004$; Table 4). The interactions between appendectomy and DM for risk of ESRD were significant $(\mathrm{P}=0.022)$.

Interaction effects between appendectomy and comorbidities or medication use on CKD and ESRD 
214 risk

215 Interaction analyses for CKD risk are shown in Figure 3A. Patients with appendectomy had a

216 higher risk of CKD compared with the control cohort in most subgroups, except patients with

217 stroke, gout, COPD, use of analgesic drugs other than NSAIDs, and use of statins. Interaction

218 analyses for ESRD risk are shown in Figure 3B. An increased risk of ESRD was also observed

219 consistently in most subgroups, except those with stroke, use of NSAIDs, and use of statins.

220 However, the interactions between appendectomy and concomitant chronic diseases or medication

221 use were not significant for any of these subgroups (all $\mathrm{P}_{\text {interaction }}>0.05$; Fig. 3A and 3B).

222

223 Discussion

224 Acute appendicitis is one of the most common surgical emergencies, with a rate of approximately

22510 cases per 10,000 people per year. ${ }^{17}$ The microbiota in the large bowel can change after 226 appendectomy, leading to dysbiosis. ${ }^{9}$ Gut dysbiosis and inflammation are underlying and linking

227 factors between CKD and DM. ${ }^{18}$ Appendectomy could worsen pre-existing dysbiosis in diabetic

228 patients, increasing the risk of ESRD development. In addition, appendectomy has been identified

229 as a risk factor for the development of acute kidney injury. ${ }^{19}$ Furthermore, many studies have

230 suggested that appendectomy may increase the risk of ulcerative colitis, colon cancer, C. difficile

231 colitis, and rheumatic arthritis. ${ }^{6-9}$ In this large, retrospective, population-based cohort study, we

232 revealed that the risks of CKD (aHR 1.13, 95\% CI 1.01-1.26, P = 0.037) and ESRD (aHR 1.59,

$23395 \%$ CI 1.06-2.37, P = 0.024) were higher among appendectomy patients than in the control

234 cohort. These results support our supposition that there are associations between appendectomy

235 and CKD and ESRD.

236 Recently, many studies have suggested that intestinal epithelial barrier structure and function are

237 impaired in CKD patients. ${ }^{20,21}$ Furthermore, progressive loss of kidney function significantly

238 contributes to intestinal dysbiosis in CKD patients. ${ }^{22.23}$ The presence of intestinal dysbiosis is

239 associated with elevated concentrations of uremic toxins. ${ }^{24-27}$ Several microbiota-derived uremic

240 retention solutes have been identified, including p-cresyl sulfate and indoxyl sulfate. ${ }^{28}$ In

241 experimental studies, indoxyl sulfate and p-cresyl sulfate activate the intrarenal renin-angiotensin

242 system, the TGF/Smad pathway, and possibly epithelial mesenchymal transformation. These

243 effects are thought to induce inflammation and tissue injury and to accelerate the development of

244 fibrosis. ${ }^{25}$ Uremic toxins have been shown to promote and further hasten kidney disease

245 progression and cardiovascular disease. ${ }^{29-34}$ The microbiota in the large bowel can change after

246 appendectomy and impaired growth of the microbiota may lead to dysbiosis. ${ }^{9}$ Dysbiosis caused by

247 appendectomy may result in a pathogenic inflammatory effect and may increase the risk of CKD.

248 We performed subgroup analysis of the risk of CKD and ESRD in patients with appendectomy

249 and matched participants (Tables 3 and 4). The interactions between sex, age group, comorbid 
250 conditions, and appendectomy for the risk of CKD and ESRD were not significant (all $\mathrm{P}_{\text {interaction }}>$ 251 0.05). However, the interaction effect of DM with appendectomy on ESRD or CKD had apparent 252 inconsistencies. Appendectomy patients with concomitant DM had a significantly increased risk 253 of ESRD (aHR 2.08, 95\% CI 1.27-3.43, P = 0.004; Table 4) and the interactions between 254 appendectomy and DM for ESRD risk were significant $(\mathrm{P}=0.022)$. However, the risk of CKD and 255 the interaction effect between appendectomy and DM for CKD risk was not obvious (Table 3). 256 Patients with DM undergoing appendectomy have significantly more comorbidities and tend to 257 have more postoperative complications. ${ }^{35}$ Inflammation is a cardinal pathogenic mechanism in 258 diabetic nephropathy. ${ }^{36,37}$ We suggest that altered immune function and inflammation caused by 259 appendectomy could worsen renal function in diabetic patients and increase the risk of ESRD. 260 The high prevalence and low awareness of CKD in Taiwan ${ }^{38}$ could be a major factor to explain 261 our finding that DM seems to be a risk factor for ESRD but not for CKD after appendectomy 262 (Tables 3 and 4). In the cohort, we also demonstrated that appendectomy showed different effects 263 across the stroke and statin-using subgroups, the interactions were insignificant (Fig. 3). In other 264 words, there was no strong evidence of different effects of appendectomy in these subpopulations. 265 Further studies are needed to confirm these findings.

266

267

\section{Limitations}

268 This study had limitations. First, the NHIRD does not include information about smoking history, 269 body mass index, family history of renal disease, blood pressure, lipid profile, glucose or uric acid concentrations, proteinuria, dietary habits, use of over-the-counter drugs or herbal remedies, or

271 data on chronic glomerulonephritis or chronic interstitial nephritis. Although we performed

272 propensity-score matching and adjusted for various confounders, these unmeasured confounders

273 might have affected our results. Second, renal outcomes were mainly identified with ICD-9-CM codes. Because CKD severity and estimated glomerular filtration rate were unknown, the number of patients with CKD and ESRD could be underestimated. However, ICD-9-CM codes are recognized as reliable indicators of CKD, ESRD, and comorbidities. Third, results derived from a retrospective cohort study are generally of lower statistical quality than those from prospective studies because of potential biases. Finally, the majority of Taiwan's population is of Chinese ethnicity; the results of this study may not be applicable to other populations.

\section{Conclusion}

282 Understanding risk factors and implementing screening of at-risk populations will increase early detection of kidney disease, allowing initiation of treatment of modifiable risk factors for ESRD, along with appropriate treatment for CKD. To our knowledge, this study is the first to show that appendectomy is a significant risk factor for CKD and ESRD. Physicians should pay careful 
286 attention to renal function prognosis in appendectomy patients, especially in patients with DM.

287 Clearly, this link needs to be validated in more specifically designed studies.

288

289

Acknowledgments

290 We thank Rebecca Tollefson, DVM, from Edanz Group (www. edanzediting. com/ac) for editing 291 a draft of this manuscript.

292

293

294

295

296

297

298

299

300

301

302

303

304

305

306

307

308

References

309 1. Nallu A, Sharma S, Ramezani A, Muralidharan J, Raj D. 2017. Gut microbiome in chronic

310 kidney disease: challenges and opportunities. Transl Res 179:24-37 DOI:

311 10.1016/j.trsl.2016.04.007.

312 2. Gansevoort RT, Correa-Rotter R, Hemmelgarn BR, Jafar TH, Heerspink HJ, Mann JF,

313 Matsushita K, Wen CP. 2013. Chronic kidney disease and cardiovascular risk: epidemiology,

314 mechanisms, and prevention. Lancet 382:339-352 DOI: 10.1016/S0140-6736(13)60595-4.

315 3. Bollinger RR, Everett ML, Palestrant D, Love SD, Lin SS, Parker W. 2003. Human

316 secretory immunoglobulin A may contribute to biofilm formation in the gut. Immunology

317 109:580-587 DOI:10.1046/j.1365-2567.2003.01700.x.

318 4. Bollinger RR, Barbas AS, Bush EL, Lin SS, Parker W. 2007. Biofilms in the normal human

319 large bowel: fact rather than fiction. Gut 56:1481-1482

320 5. Guinane CM, Tadrous A, Fouhy F, Ryan CA, Dempsey EM, Murphy B, Andrews E, Cotter

321 PD, Stanton C, Ross RP. 2013. Microbial composition of human appendices from patients 
322 following appendectomy. MBio 4:e00366-12 DOI: 10.1128/mBio.00366-12.

323 6. Sanders NL, Bollinger RR, Lee R, Thomas S, Parker W. 2013. Appendectomy and

324 Clostridium difficile colitis: relationships revealed by clinical observations and immunology.

325 World J Gastroenterol 19:5607-5614 DOI: 10.3748/wjg.v19.i34.5607.

326 7. Tzeng YM, Kao LT, Kao S, Lin HC, Tsai MC, Lee CZ. 2015. An appendectomy increases

327 the risk of rheumatoid arthritis: a five-year follow-up study. PloS One 10:e0126816 DOI:

328 10.1371/journal.pone.0126816.

329 8. Roblin X, Neut C, Darfeuille-Michaud A, Colombel JF. 2012. Local appendiceal dysbiosis:

330 the missing link between the appendix and ulcerative colitis? Gut 61:635-636 DOI:

331 10.1136/gutjnl-2011-300576.

332 9. Wu SC, Chen WT, Muo CH, Ke TW, Fang CW, Sung FC. 2015. Association between

333 appendectomy and subsequent colorectal cancer development: an Asian population study. PLoS

334 One 10:e118411 DOI: 10.1371/journal.pone.0118411.

335 10. Cheng CL, Kao YH, Lin SJ, Lee CH, Lai ML. 2011. Validation of the national health

336 insurance research database with ischemic stroke cases in Taiwan. Pharmacoepidemiol Drug Saf

337 20:236-242 DOI: 10.1002/pds.2087.

338 11. Cheng CL, Lee CH, Chen PS, Li YH, Lin SJ, Yang YH. 2014. Validation of acute

339 myocardial infarction cases in the national health insurance research database in Taiwan. $J$

340 Epidemiol 24:500-507 DOI: 10.2188/jea.JE20140076.

341 12. Hsu TW, Liu JS, Hung SC, Kuo KL, Chang YK, Chen YC, Hsu CC, Tarng DC. 2014.

342 Renoprotective effect of renin-angiotensin-aldosterone system blockade in patients with

343 predialysis advanced chronic kidney disease, hypertension, and anemia. JAMA Intern Med

344 174:347-354 DOI: 10.1001/jamainternmed.2013.12700.

345 13. Wu CL, Tsai CC, Kor CT, Tarng DC, Lian IB, Yang TH, Chiu PF, Chang CC. 2016. Stroke

346 and risks of development and progression of kidney diseases and end-stage renal disease: a

347 nationwide population-based cohort study. PloS One 11:e0158533 DOI:

348 10.1371/journal.pone.0158533.

349 14. Wu CL, Kor CT, Chiu PF, Tsai CC, Lian IB, Yang TH, Tarng DC, Chang CC. 2017. Long-

350 term renal outcomes in patients with traumatic brain injury: a nationwide population-based

351 cohort study. PloS One 12:e171999 DOI: 10.1371/ journal.pone.0171999.

352 15. Weng SC, Wu CL, Kor CT, Chiu PF, Wu MJ, Chang CC, Tarng DC. 2017. Migraine and

353 subsequent chronic kidney disease risk: a nationwide population-based cohort study. BMJ Open

354 7:e018483 DOI: 10.1136/ bmjopen-2017-018483.

355 16. Deyo RA, Cherkin DC, Ciol MA. 1992. Adapting a clinical comorbidity index for use with

356 ICD-9-CM administrative databases. J Clin Epidemiol 45:613-619 DOI: 10.1016/0895-

357 4356(92)90133-8. 
358 17. Buckius MT, McGrath B, Monk J, Grim R, Bell T, Ahuja V. 2012. Changing epidemiology

359 of acute appendicitis in the United States: study period 1993-2008. J Surg Res 175:185-190 DOI:

360 10.1016/j.jss.2011.07.017.

361 18. Sabatino A, Regolisti G, Cosola C, Gesualdo L, Fiaccadori E. 2017. Intestinal microbiota

362 in type 2 diabetes and chronic kidney disease. Curr Diab Rep 17:16 DOI: 10.1007/s11892-017-

363 0841-z.

364 19. Kim M, Brady JE, Li G. 2014. Variations in the risk of acute kidney injury across

365 intraabdominal surgery procedures. Anesth Analg 119:1121-1132 DOI:

366 10.1213/ANE.0000000000000425.

367 20. Vaziri ND, Zhao YY, Pahl MV. 2016. Altered intestinal microbial flora and impaired

368 epithelial barrier structure and function in CKD: the nature, mechanisms, consequences and

369 potential treatment. Nephrol Dial Transplant 31:737-746 DOI: 10.1093/ndt/gfv095.

370 21. Vaziri ND, Wong J, Pahl M, Piceno YM, Yuan J, DeSantis TZ, Ni Z, Nguyen TH,

371 Andersen GL. 2013. Chronic kidney disease alters intestinal microbial flora. Kidney Int 83:308-

372315 DOI: 10.1038/ki.2012.345.

373 22. Jiang S, Xie S, Lv D, Wang P, He H, Zhang T, Zhou Y, Lin Q, Zhou H, Jiang J, Nie J, Hou

374 F, Chen Y. 2017. Alteration of the gut microbiota in Chinese population with chronic kidney

375 disease. Sci Rep 7:2870 DOI: 10.1038/s41598-017-02989-2.

376 23. Anders HJ, Andersen K, Stecher B. 2013. The intestinal microbiota, a leaky gut, and

377 abnormal immunity in kidney disease. Kidney Int 83:1010-1016 DOI: 10.1038/ki.2012.440.

378 24. Evenepoel P, Meijers BK, Bammens BR, Verbeke K. 2009. Uremic toxins originating from

379 colonic microbial metabolism. Kidney Int Suppl 114:S12-S19 DOI: 10.1038/ki.2009.402.

380 25. Pan W, Kang Y. 2018. Gut microbiota and chronic kidney disease: implications for novel

381 mechanistic insights and therapeutic strategies. Int Urol Nephrol 50:289-299 DOI:

382 10.1007/s11255-017-1689-5.

383 26. Ramezani A, Raj DS. 2014. The gut microbiome, kidney disease, and targeted

384 interventions. J Am Soc Nephrol 25:657-670 DOI: 10.1681/ ASN.2013080905.

385 27. Koppe L, Mafra D, Fouque D. 2015. Probiotics and chronic kidney disease. Kidney Int

386 88:958-966 DOI: 10.1038/ki.2015.255.

387 28. Poesen R, Evenepoel P, de Loor H, Delcour JA, Courtin CM, Kuypers D, Augustijns P,

388 Verbeke K, Meijers B. 2016. The influence of prebiotic arabinoxylan oligosaccharides on

389 microbiota derived uremic retention solutes in patients with chronic kidney disease: a

390 randomized controlled trial. PLoS One 11:e153893 DOI: 10.1371/journal.pone.0153893.

391 29. Wu IW, Hsu KH, Lee CC, Sun CY, Hsu HJ, Tsai CJ, Tzen CY, Wang YC, Lin CY, Wu

392 MS. 2011. p-Cresyl sulphate and indoxyl sulphate predict progression of chronic kidney disease.

393 Nephrol Dial Transplant 26:938-947 DOI: 10.1093/ndt/gfq580. 
394 30. Aronov PA, Luo FJ, Plummer NS, Quan Z, Holmes S, Hostetter TH, Meyer TW. 2011.

395 Colonic contribution to uremic solutes. J Am Soc Nephrol 22:1769-1776 DOI:

396 10.1681/ASN.2010121220.

397 31. Lin CJ, Chen HH, Pan CF, Chuang CK, Wang TJ, Sun FJ, Wu CJ. 2011. p-Cresylsulfate 398 and indoxyl sulfate level at different stages of chronic kidney disease. J Clin Lab Anal 25:191399197 DOI: $10.1002 /$ jcla.20456.

400 32. Sun CY, Chang SC, Wu MS. 2012. Uremic toxins induce kidney fibrosis by activating 401 intrarenal renin-angiotensin-aldosterone system associated epithelial-to-mesenchymal transition. 402 PLoS One 7:e34026 DOI: 10.1371/ journal.pone.0034026.

403 33. Mutsaers HA, Stribos EG, Glorieux G, Vanholder R, Olinga P. 2015. Chronic kidney 404 disease and fibrosis: the role of uremic retention solutes. Front Med 2:60 DOI: 405 10.3389/fmed.2015.00060.

406 34. Meijers BK, Evenepoel P. 2011. The gut-kidney axis: indoxyl sulfate, p-cresyl sulfate and 407 CKD progression. Nephrol Dial Transplant 26:759-761 DOI: 10.1093/ndt/gfq818.

408 35. Bach L, Donovan A, Loggins W, Thompson S, Richmond B. 2016. Appendicitis in 409 diabetics: predictors of complications and their incidence. Am Surg 82:753-758.

410 36. Barutta F, Bruno G, Grimaldi S, Gruden G. 2015. Inflammation in diabetic nephropathy:

411 moving toward clinical biomarkers and targets for treatment. Endocrine 48:730-742 DOI:

412 10.1007/s12020-014-0437-1.

413 37. Lim AK, Tesch GH. 2012. Inflammation in diabetic nephropathy. Mediators Inflamm 414 2012:146154 DOI: 10.1155/2012/146154.

415 38. Hsu CC, Hwang SJ, Wen CP, Chang HY, Chen T, Shiu RS, Horng SS, Chang YK, Yang 416 WC. 2006. High prevalence and low awareness of CKD in Taiwan: a study on the relationship 417 between serum creatinine and awareness from a nationally representative survey. Am J Kidney 418 Dis 48:727-738 DOI: 10.1053/j.ajkd.2006.07.018.

419

420

421

422

423 Figure legends

424 Figure 1. Flowchart of subject selection process.

425 Figure 2. A: Cumulative incidence curve of chronic kidney disease (CKD) in patients after 426 appendectomy compared with control cohort. B: Cumulative incidence curve of end-stage renal 427 disease (ESRD) in patients after appendectomy compared with control cohort.

428 Figure 3. A: Interaction effects between appendectomy and comorbidities or medication use on 429 risk of chronic kidney disease (CKD). B: Interaction effect between appendectomy and 
430 comorbidities or medication use on risk of end-stage renal disease (ESRD).

431 Table Legends

432 Table 1. Patient Demographics.

433 Table 2. Incidence Rate and Risk of Chronic Kidney Disease (CKD) and End-Stage Renal

434 Disease (ESRD) in Patients with Appendectomy and Matched Control Group.

435 Table 3. Subgroup Analyses of Chronic Kidney Disease Risk in Patients with Appendectomy

436 and Matched Control Group.

437 Table 4. Subgroup Analyses of End-Stage Renal Disease Risk in Patients with Appendectomy 438 and Matched Control Group. 


\section{Table $\mathbf{1}$ (on next page)}

Patient demographics 
Table 1. Demographic

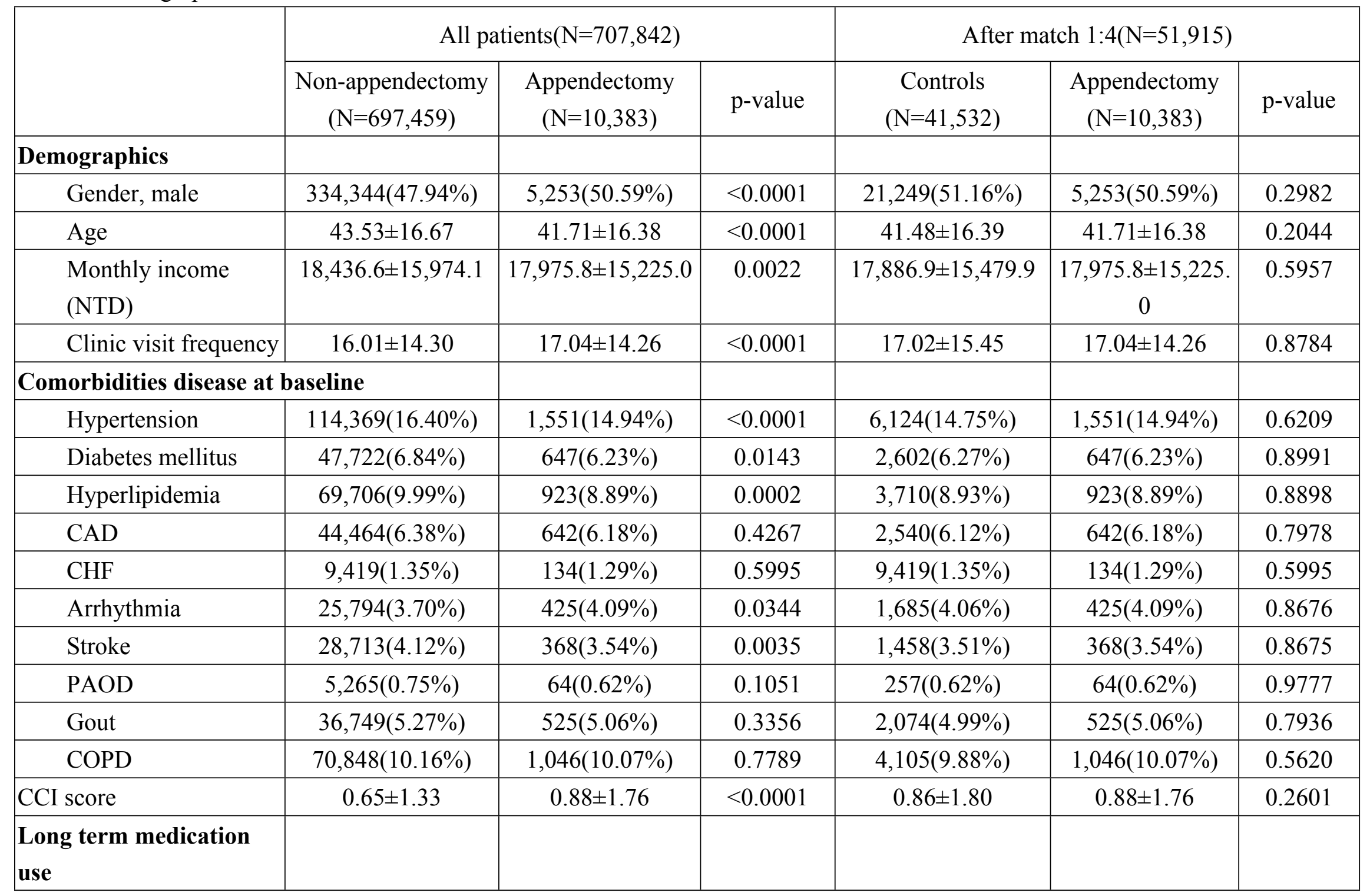




\begin{tabular}{|c|c|c|c|c|c|c|}
\hline Anti-diabetic agents & $32,681(4.69 \%)$ & $411(3.96 \%)$ & 0.0005 & $1,595(3.84 \%)$ & $411(3.96 \%)$ & 0.5769 \\
\hline $\begin{array}{l}\text { Antihypertensive } \\
\text { drug }\end{array}$ & $110,224(15.80 \%)$ & $1,492(14.37 \%)$ & $<0.0001$ & $5,924(14.26 \%)$ & $1,492(14.37 \%)$ & 0.7826 \\
\hline Diuretics & $27,619(3.96 \%)$ & $368(3.54 \%)$ & 0.0310 & $1,557(3.75 \%)$ & $368(3.54 \%)$ & 0.3236 \\
\hline ACEIs/ARBs & $51,323(7.36 \%)$ & $617(5.94 \%)$ & $<0.0001$ & $2,693(6.48 \%)$ & $617(5.94 \%)$ & 0.0433 \\
\hline Beta-blockers & $54,829(7.86 \%)$ & $724(6.97 \%)$ & 0.0008 & $2,940(7.08 \%)$ & $724(6.97 \%)$ & 0.7062 \\
\hline NSAIDs & $41,546(5.96 \%)$ & $667(6.42 \%)$ & 0.0460 & $2,593(6.24 \%)$ & $667(6.42 \%)$ & 0.4975 \\
\hline $\begin{array}{c}\text { Analgesic drugs other } \\
\text { than NSAIDs }\end{array}$ & $23,206(3.33 \%)$ & $441(4.25 \%)$ & $<0.0001$ & $1,697(4.09 \%)$ & $441(4.25 \%)$ & 0.4594 \\
\hline Statins & $24,292(3.48 \%)$ & $279(2.69 \%)$ & $<0.0001$ & $1,125(2.71 \%)$ & $279(2.69 \%)$ & 0.9031 \\
\hline Propensity score & $0.015 \pm 0.005$ & $0.016 \pm 0.008$ & $<0.0001$ & $0.016 \pm 0.008$ & $0.016 \pm 0.008$ & 0.9999 \\
\hline \multicolumn{7}{|l|}{ Outcome } \\
\hline CKD & $26,298(3.77 \%)$ & $451(4.34 \%)$ & 0.0024 & $1,430(3.44 \%)$ & $451(4.34 \%)$ & $<0.0001$ \\
\hline ESRD & $1,544(0.22 \%)$ & $35(0.34 \%)$ & 0.0131 & $75(0.18 \%)$ & $35(0.34 \%)$ & 0.0019 \\
\hline Death & $86,965(12.47 \%)$ & $1,129(10.87 \%)$ & $<0.0001$ & $5,300(12.76 \%)$ & $1,129(10.87 \%)$ & $<0.0001$ \\
\hline $\begin{array}{l}\text { Subsequent death } \\
\text { after ESRD or } \\
\text { CKD }\end{array}$ & $9640(1.38 \%)$ & $145(1.40 \%)$ & 0.9346 & $533(1.28 \%)$ & $145(1.39 \%)$ & 0.3897 \\
\hline $\begin{array}{l}\text { Death without } \\
\text { CKD or ESRD }\end{array}$ & $77325(11.09 \%)$ & $984(9.48 \%)$ & $<0.0001$ & $4767(11.48 \%)$ & $984(9.47 \%)$ & $<0.0001$ \\
\hline
\end{tabular}

2 Abbreviations: NTD, new Taiwan dollars; ACEI, Angiotensin-converting-enzyme inhibitor; ARB, Angiotensin II receptor blocker;

$3 \mathrm{CAD}$, coronary artery disease; CHF, congestive heart failure; CCI, Charlson's comorbidity index; CKD, chronic kidney disease;

4 ESRD, end-stage renal disease; NSAIDs, Non-steroidal anti-inflammatory drugs; PAOD, peripheral artery occlusive disease; COPD,

5 chronic obstructive pulmonary disease; 


\section{Table 2 (on next page)}

Incidence rate and risk of CKD and ESRD.

Incidence rate and risk of Chronic Kidney Disease (CKD) and End-Stage Renal Disease (ESRD) in patients with appendectomy and matched participants. 
Table 2. Incidence Rate and Risk of Chronic Kidney Disease (CKD) and End-Stage Renal Disease (ESRD) in Patients with Appendectomy and Matched Participants

\begin{tabular}{|c|c|c|c|c|c|c|c|c|c|}
\hline & \multirow{2}{*}{$\begin{array}{l}\text { Events } \\
\text { (no.) }\end{array}$} & \multirow[t]{2}{*}{$\mathrm{PY}^{\dagger}$} & \multirow[t]{2}{*}{ Incidence } & \multicolumn{2}{|c|}{ Model 1} & \multicolumn{2}{|c|}{ Model 2} & \multicolumn{2}{|c|}{ Model 3} \\
\hline & & & & $\begin{array}{c}\text { HR } \\
(95 \% \mathrm{CI})\end{array}$ & P-value & $\begin{array}{l}\text { Adj. HR } \\
(95 \% \mathrm{CI})\end{array}$ & P-value & $\begin{array}{l}\text { Adj. HR } \\
(95 \% \mathrm{CI})\end{array}$ & P-value \\
\hline \multicolumn{10}{|l|}{ CKD } \\
\hline Control cohort & 1,430 & $241,152.6$ & $\begin{array}{c}5.93 \\
(5.62,6.24) \\
\end{array}$ & \multicolumn{2}{|c|}{ reference } & \multicolumn{2}{|c|}{ reference } & \multicolumn{2}{|c|}{ reference } \\
\hline $\begin{array}{c}\text { Appendectomy } \\
\text { cohort }\end{array}$ & 451 & $69,120.0$ & $\begin{array}{c}6.52 \\
(5.92,7.13)\end{array}$ & $\begin{array}{c}1.145 \\
(1.030,1.273)\end{array}$ & 0.0120 & $\begin{array}{c}1.125 \\
(1.012,1.251)\end{array}$ & 0.0291 & $\begin{array}{c}1.125 \\
(1.007,1.256)\end{array}$ & 0.0365 \\
\hline \multicolumn{10}{|l|}{ ESRD } \\
\hline Control cohort & 75 & $245,459.0$ & $\begin{array}{c}0.31 \\
(0.24,0.37) \\
\end{array}$ & \multicolumn{2}{|c|}{ reference } & \multicolumn{2}{|c|}{ reference } & \multicolumn{2}{|c|}{ reference } \\
\hline $\begin{array}{c}\text { Appendectomy } \\
\text { cohort }\end{array}$ & 35 & $70,716.2$ & $\begin{array}{c}0.49 \\
(0.33,0.66)\end{array}$ & $\begin{array}{c}1.653 \\
(1.107,2.468)\end{array}$ & 0.0140 & $\begin{array}{c}1.622 \\
(1.087,2.421)\end{array}$ & 0.0179 & $\begin{array}{c}1.588 \\
(1.064,2.371)\end{array}$ & 0.0237 \\
\hline
\end{tabular}

Model 1: Propensity-score matched.

Model 2: Adjusted for propensity score.

Model 3: Adjusted for all variables listed in Table 1.

†PY: person-years. " per 1000 person-years. HR: hazard ratio; Adj. HR: adjusted hazard ratio; CI: confidence interval. 


\section{Table 3(on next page)}

Subgroup Analyses of Chronic Kidney Disease Risk.

Subgroup Analyses of Chronic Kidney Disease Risk in Patients with Appendectomy and Matched Control Group. 
Table 3. Subgroup Analyses of Chronic Kidney Disease Risk in Patients with Appendectomy and Matched Control Group

\begin{tabular}{|c|c|c|c|c|c|c|c|c|c|}
\hline \multirow[t]{2}{*}{ Subgroup } & \multicolumn{2}{|c|}{$\begin{array}{l}\text { Subjects without } \\
\text { appendectomy }\end{array}$} & \multicolumn{2}{|c|}{$\begin{array}{l}\text { Subjects with } \\
\text { appendectomy }\end{array}$} & \multicolumn{5}{|c|}{ Compared with control group } \\
\hline & $\begin{array}{l}\text { Total } \\
\text { no. }\end{array}$ & Event (no.) & $\begin{array}{c}\text { Total } \\
\text { no. }\end{array}$ & Event (no.) & aHR $(95 \% \mathrm{CI})^{\S}$ & P-value & aHR $(95 \% \text { CI })^{\ddagger}$ & P-value & $\mathrm{P}_{\text {interaction }}$ \\
\hline Sex & & & & & & & & & 0.4765 \\
\hline Female & 20,283 & 592 & 5,130 & 193 & $1.080(0.916,1.274)$ & 0.3576 & $1.068(0.901,1.266)$ & 0.4467 & \\
\hline Male & 21,249 & 838 & 5,253 & 258 & $1.172(1.019,1.347)$ & 0.0259 & $1.160(1.003,1.342)$ & 0.0452 & \\
\hline Age, years & & & & & & & & & 0.8848 \\
\hline$<30$ & 12,470 & 69 & 3,057 & 17 & $0.890(0.521,1.521)$ & 0.6696 & $0.933(0.544,1.600)$ & 0.8013 & \\
\hline $30-65$ & 24,693 & 780 & 6,176 & 248 & $1.133(0.983,1.306)$ & 0.0855 & $1.122(0.970,1.298)$ & 0.1225 & \\
\hline$\geq 65$ & 4,369 & 581 & 1,150 & 186 & $1.111(0.942,1.310)$ & 0.2110 & $1.096(0.925,1.298)$ & 0.2918 & \\
\hline $\begin{array}{l}\text { Comorbiditie } \\
\mathrm{S}(\text { no.) }\end{array}$ & & & & & & & & & 0.2755 \\
\hline 0 & 29,761 & 446 & 7,314 & 160 & $1.265(1.054,1.518)$ & 0.0114 & $1.293(1.078,1.551)$ & 0.0057 & \\
\hline $1-2$ & 8,119 & 527 & 2,178 & 157 & $0.965(0.808,1.154)$ & 0.6990 & $0.953(0.796,1.142)$ & 0.6032 & \\
\hline$\geq 3$ & 3,652 & 457 & 891 & 134 & $1.084(0.894,1.313)$ & 0.4122 & $1.088(0.895,1.322)$ & 0.3968 & \\
\hline Diabetes melli & & & & & & & & & 0.5547 \\
\hline No & 38,930 & 1,020 & 9,736 & 313 & $1.091(0.961,1.238)$ & 0.1790 & $1.102(0.968,1.253)$ & 0.1420 & \\
\hline Yes & 2,602 & 410 & 647 & 138 & $1.093(0.900,1.326)$ & 0.3698 & $1.122(0.921,1.367)$ & 0.2534 & \\
\hline
\end{tabular}

${ }^{\S}$ Model was adjusted for propensity score.

*Model was adjusted for all variables listed in Table 1. 
Table 4. Subgroup Analyses of End-Stage Renal Disease Risk in Patients with Appendectomy and Matched Control Group

\begin{tabular}{|c|c|c|c|c|c|c|c|c|c|}
\hline \multirow[t]{2}{*}{ Subgroup } & \multicolumn{2}{|c|}{$\begin{array}{l}\text { Subjects without } \\
\text { appendectomy }\end{array}$} & \multicolumn{2}{|c|}{$\begin{array}{l}\text { Subjects with } \\
\text { appendectomy }\end{array}$} & \multicolumn{5}{|c|}{ Compared with control group } \\
\hline & Total & Event & Total & Event & $\operatorname{aHR}(95 \% \mathrm{CI})^{\S}$ & P-value & $\operatorname{aHR}(95 \% \mathrm{CI})^{\ddagger}$ & $\mathrm{P}$-value & $\mathrm{P}_{\text {interaction }}$ \\
\hline Sex & & & & & & & & & 0.9338 \\
\hline Female & 20,283 & 40 & 5,130 & 20 & $1.546(0.903,2.648)$ & 0.1125 & $1.679(0.965,2.922)$ & 0.0666 & \\
\hline Male & 21,249 & 35 & 5,253 & 15 & $1.624(0.883,2.988)$ & 0.1190 & $1.625(0.863,3.060)$ & 0.1325 & \\
\hline Age, years & & & & & & & & & 0.0715 \\
\hline$<30$ & 12,470 & 2 & 3,057 & 2 & $\begin{array}{c}3.049(0.389 \\
23.920)\end{array}$ & 0.2887 & $3.792(0.594,24.204)$ & 0.1587 & \\
\hline $30-65$ & 24,693 & 34 & 6,176 & 21 & $2.118(1.234,3.635)$ & 0.0065 & $2.048(1.173,3.573)$ & 0.0117 & \\
\hline$\geq 65$ & 4,369 & 39 & 1,150 & 12 & $1.000(0.526,1.901)$ & 0.9994 & $0.937(0.487,1.800)$ & 0.8441 & \\
\hline $\begin{array}{l}\text { Comorbiditie } \\
\text { S (no.) }\end{array}$ & & & & & & & & & 0.8698 \\
\hline 0 & 29,761 & 13 & 7,314 & 6 & $1.583(0.594,4.216)$ & 0.3581 & $1.501(0.559,4.032)$ & 0.4204 & \\
\hline $1-2$ & 8,119 & 21 & 2,178 & 10 & $1.333(0.636,2.791)$ & 0.4463 & $1.300(0.603,2.801)$ & 0.5029 & \\
\hline$\geq 3$ & 3,652 & 41 & 891 & 19 & $1.618(0.935,2.797)$ & 0.0852 & $1.651(0.959,2.840)$ & 0.0702 & \\
\hline Diabetes mell & & & & & & & & & 0.0222 \\
\hline No & 38,930 & 35 & 9,736 & 8 & $0.804(0.372,1.735)$ & 0.5777 & $0.829(0.386,1.780)$ & 0.6302 & \\
\hline Yes & 2,602 & 40 & 647 & 27 & $1.964(1.207,3.195)$ & 0.0066 & $2.082(1.266,3.425)$ & 0.0039 & \\
\hline
\end{tabular}

${ }^{\S}$ Model was adjusted for propensity score.

Model was adjusted for all variables listed in Table 1. 


\section{Table 4 (on next page)}

Subgroup Analysesof End-Stage Renal Disease Risk.

Subgroup Analyses of End-Stage Renal Disease Risk in Patients with Appendectomy and Matched Control Group. 
Table 4. Subgroup Analyses of End-Stage Renal Disease Risk in Patients with Appendectomy and Matched Control Group

\begin{tabular}{|c|c|c|c|c|c|c|c|c|c|}
\hline \multirow[t]{2}{*}{ Subgroup } & \multicolumn{2}{|c|}{$\begin{array}{c}\text { Subjects without } \\
\text { appendectomy }\end{array}$} & \multicolumn{2}{|c|}{$\begin{array}{l}\text { Subjects with } \\
\text { appendectomy }\end{array}$} & \multicolumn{5}{|c|}{ Compared with control group } \\
\hline & Total & Event & Total & Event & aHR $(95 \% \mathrm{CI})^{\S}$ & P-value & $\operatorname{aHR}(95 \% \mathrm{CI})$ & P-value & $\mathrm{P}_{\text {interaction }}$ \\
\hline Sex & & & & & & & & & 0.9338 \\
\hline Female & 20,283 & 40 & 5,130 & 20 & $1.546(0.903,2.648)$ & 0.1125 & $1.679(0.965,2.922)$ & 0.0666 & \\
\hline Male & 21,249 & 35 & 5,253 & 15 & $1.624(0.883,2.988)$ & 0.1190 & $1.625(0.863,3.060)$ & 0.1325 & \\
\hline Age, years & & & & & & & & & 0.0715 \\
\hline$<30$ & 12,470 & 2 & 3,057 & 2 & $\begin{array}{c}3.049(0.389 \\
23.920)\end{array}$ & 0.2887 & $3.792(0.594,24.204)$ & 0.1587 & \\
\hline $30-65$ & 24,693 & 34 & 6,176 & 21 & $2.118(1.234,3.635)$ & 0.0065 & $2.048(1.173,3.573)$ & 0.0117 & \\
\hline$\geq 65$ & 4,369 & 39 & 1,150 & 12 & $1.000(0.526,1.901)$ & 0.9994 & $0.937(0.487,1.800)$ & 0.8441 & \\
\hline $\begin{array}{l}\text { Comorbidities } \\
\text { (no.) }\end{array}$ & & & & & & & & & 0.8698 \\
\hline 0 & 29,761 & 13 & 7,314 & 6 & $1.583(0.594,4.216)$ & 0.3581 & $1.501(0.559,4.032)$ & 0.4204 & \\
\hline $1-2$ & 8,119 & 21 & 2,178 & 10 & $1.333(0.636,2.791)$ & 0.4463 & $1.300(0.603,2.801)$ & 0.5029 & \\
\hline$\geq 3$ & 3,652 & 41 & 891 & 19 & $1.618(0.935,2.797)$ & 0.0852 & $1.651(0.959,2.840)$ & 0.0702 & \\
\hline Diabetes melli & & & & & & & & & 0.0222 \\
\hline No & 38,930 & 35 & 9,736 & 8 & $0.804(0.372,1.735)$ & 0.5777 & $0.829(0.386,1.780)$ & 0.6302 & \\
\hline Yes & 2,602 & 40 & 647 & 27 & $1.964(1.207,3.195)$ & 0.0066 & $2.082(1.266,3.425)$ & 0.0039 & \\
\hline
\end{tabular}

2 Model was adjusted for propensity score.

3 Model was adjusted for all variables listed in Table 1. 
Figure 1

Flowchart.

Flowchart of subject selection process

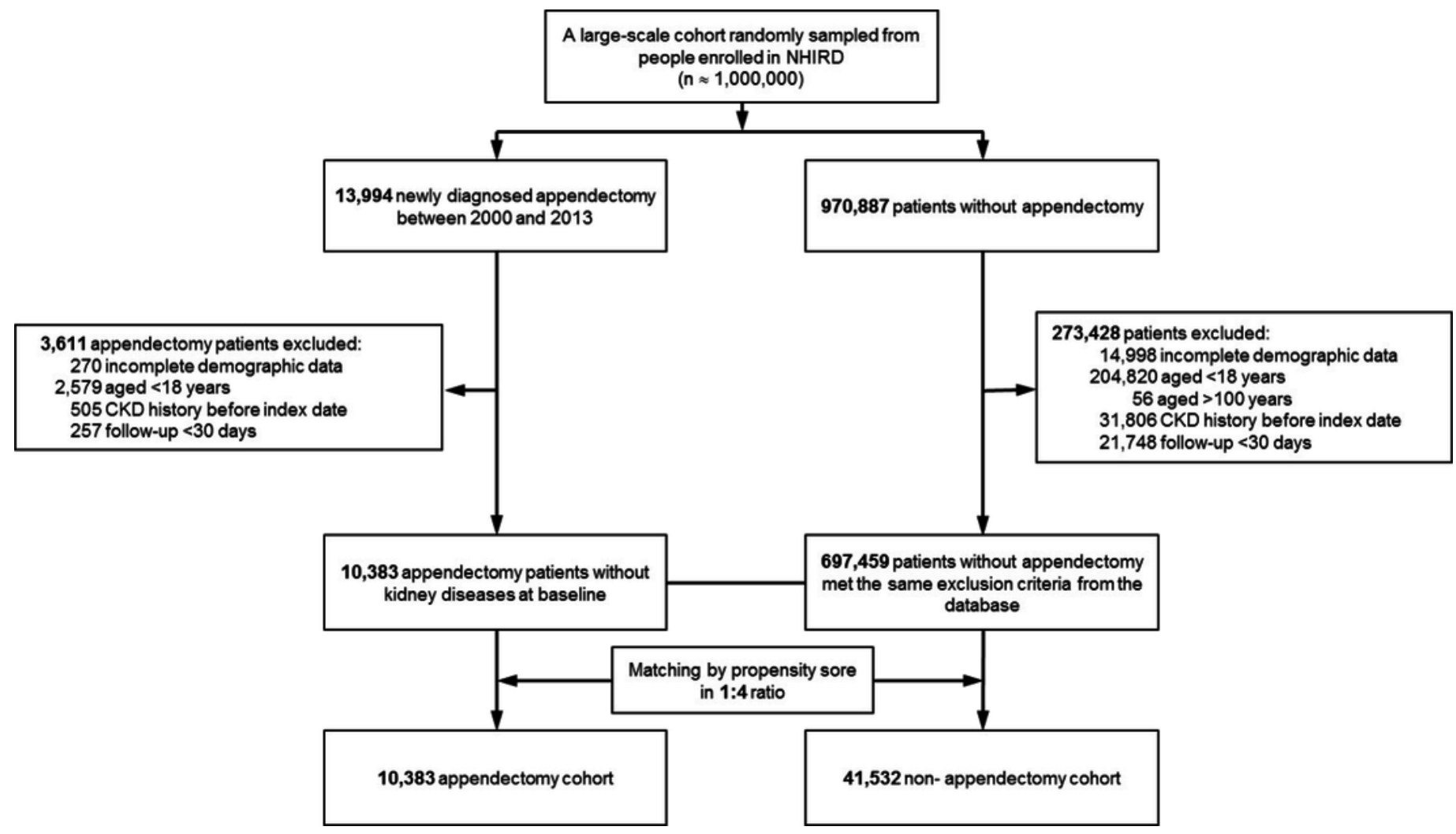


Figure 2

Cumulative incidence curve of CKD and ESRD

(A) Cumulative incidence curve of CKD for patients after appendectomy compared with control cohort. (B) Cumulative incidence curves of ESRD for patients after appendectomy compared with control cohort. 
A

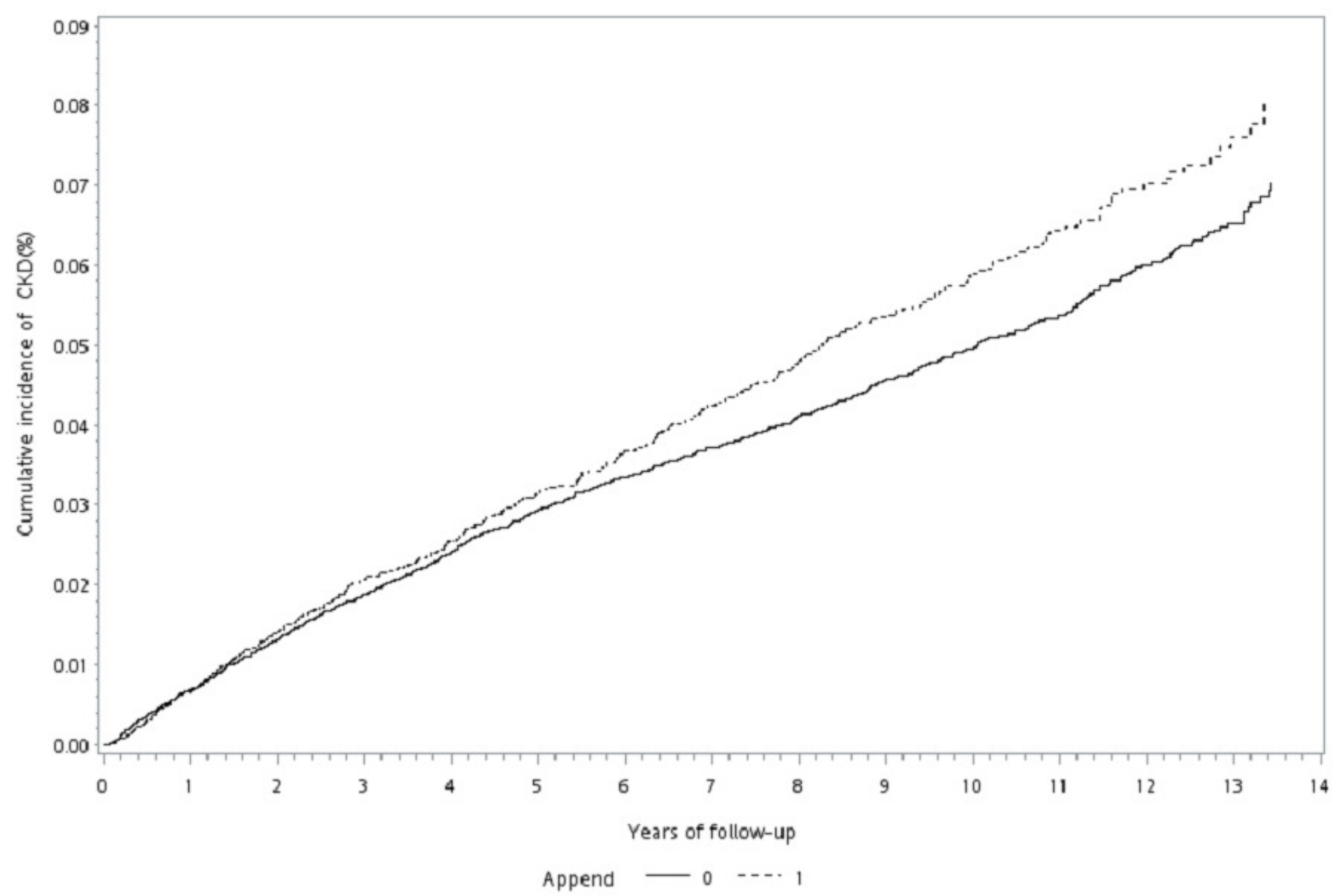

B

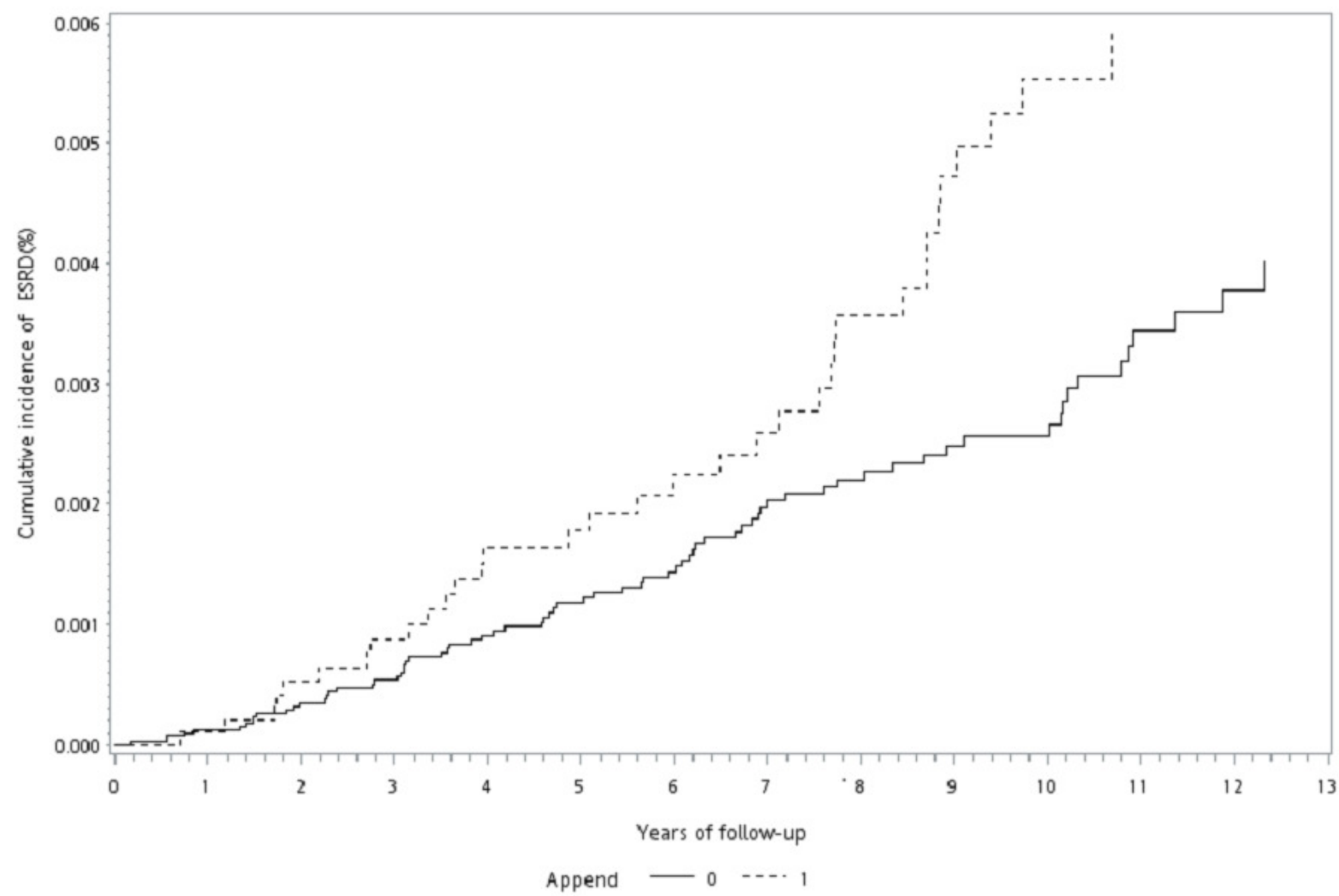

PeerJ reviewing PDF | (2018:02:23928:3:0:NEW 24 May 2018) 


\section{Figure 3}

Interaction effects between appendectomy and comorbidities or medication.

(A) Interaction effects between appendectomy and comorbidities or medication use on CKD risk.

(B) Interaction effect between appendectomy and comorbidities or medication use on ESRD risk. 


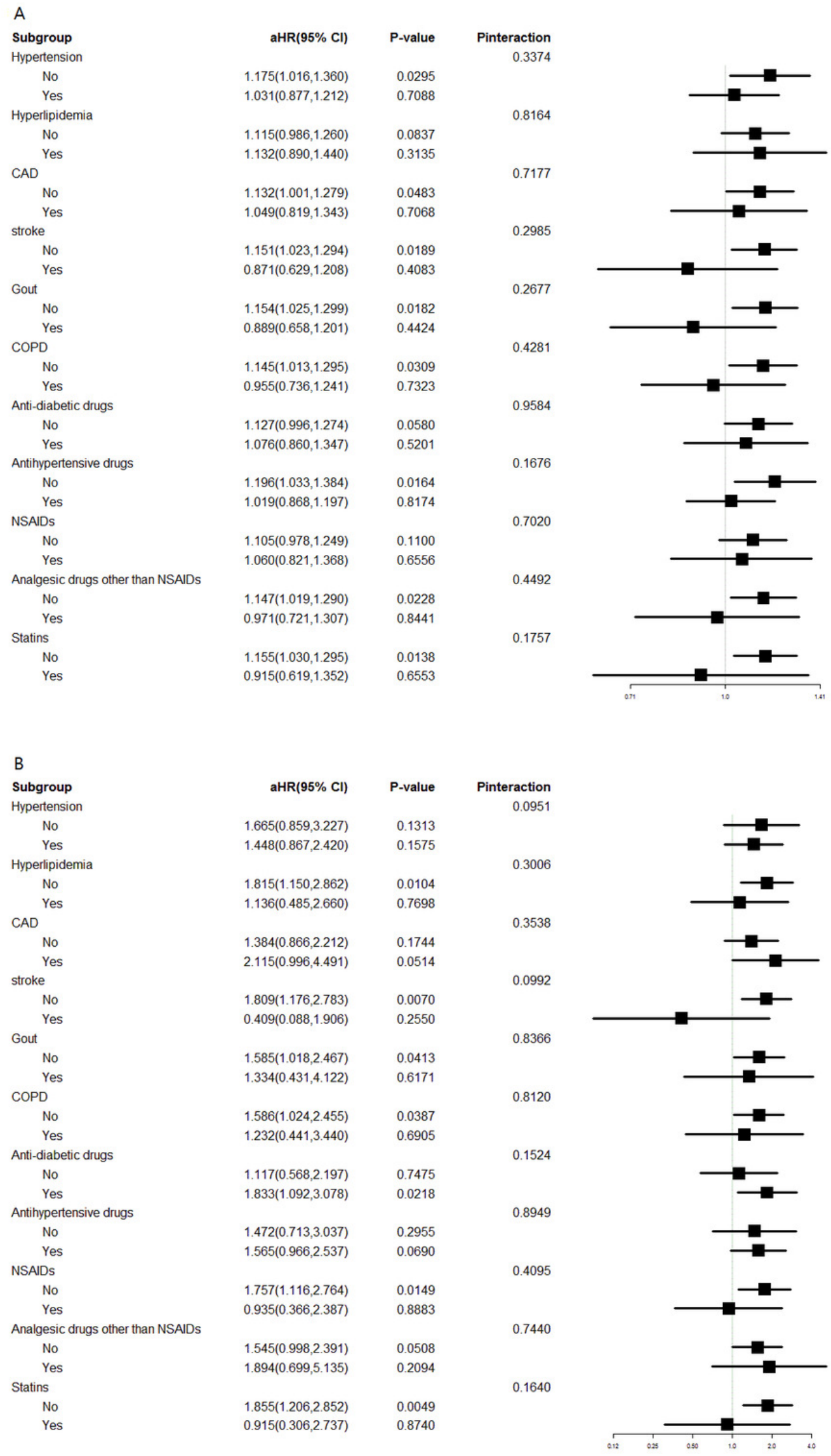

